
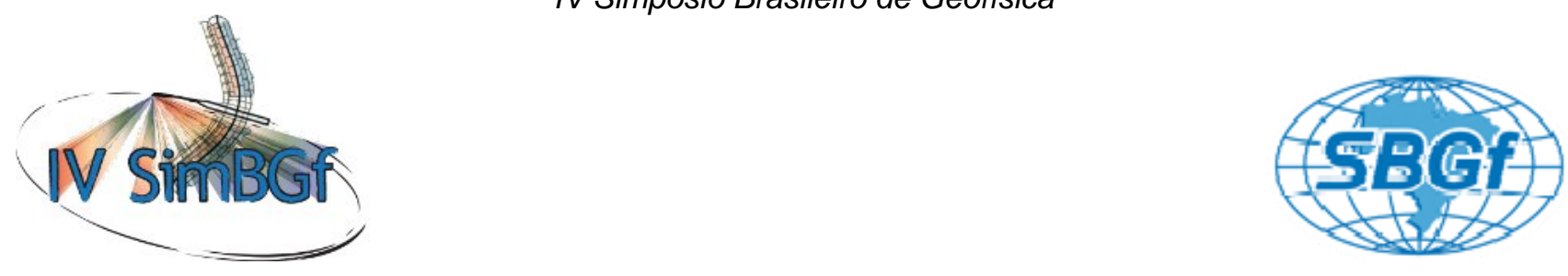

\title{
Modelagem e interpretação de dados aerogeofísicos de alta resolução na geração de alvos para follow-up para ouro no terreno granito-greenstone Rio Maria, Pará.
}

Ezequiel Costa e Silva (*), Reinarda Mineração/Universidade de Brasília; Adalene Moreira Silva, Catarina L. B. Toledo Universidade de Brasília; Augusto Mol, Reinarda Mineração

Copyright 2010, SBGf - Sociedade Brasileira de Geofísica

Este texto foi preparado para a apresentação no IV Simpósio Brasileiro de Geofísica, Brasília, 14 a 17 de novembro de 2010. Seu conteúdo foi revisado pelo Comitê Técnico do IV SimBGf, mas não necessariamente representa a opinião da SBGf ou de seus associados. É proibida a reprodução total ou parcial deste material para propósitos comerciais sem prévia autorização da SBGf.

\begin{abstract}
This paper discusses the processing and interpretation of high-resolution airborne magnetic gradiometers and gamma-ray spectrometric surveys in order to generate prospecting targets for orogenic gold mineralization over the Rio Maria Granitoid-Greenstone belt, located to the southeast of Para state. Gratiometer magnetic survey associated with high-resolution gamma-ray spectrometric data show a technological advance on available geophysical technology for low magnetic gradient structures of interest of mineral exploration. The combinaiton of measured gradients ( $\mathrm{Gx}$ and $\mathrm{Gy}$ ) with products derived from combination $\mathrm{K}$, Th and $\mathrm{U}$ channels has shown effectiveness on selecting targets to follow-up tropical terrains.
\end{abstract}

\section{Introdução}

Significativos avanços têm sido realizados nos últimos anos na área de exploração mineral em geoquímica, geofísica, sensores remotos e na integração de dados. Essas tecnologias tem sido uma ótima ferramenta para a descoberta de novos depósitos de ouro em diversos ambientes metalogenéticos. A pesquisa mineral se preocupa em definir o modelo dos depósitos de ouro conhecidos, bem como em integrar as diversas técnicas exploratórias com a geologia, visando à identificação e caracterização da zona de minério (Robert et al. 2007). O projeto aqui proposto visa à aplicação de técnicas de processamento e análise integrada dos dados aerogeofísicos de alta resolução e sua aplicação no detalhamento litológico, estrutural do greenstone belt Andorinhas, com o intuito de definir áreas favoráveis para mineralizações auríferas. Para tanto, será efetuada uma análise espacial de variáveis indicativas da existência de concentrações minerais na região da Província Rio Maria.

A área estudada esta localizada a parte sul da Província Mineral de Carajás, e faz parte do terreno granitogreenstone Rio Maria (Figura 1). A área abrange os municípios de Xinguara, Rio Maria e Floresta do Araguaia (PA), distando aproximadamente $260 \mathrm{~km}$ a sudoeste de Marabá.

\section{Contexto geológico}

A Província Mineral de Carajás, localizada na porção sudeste do Pará na borda do Cráton Amazônico (Tassinari \& Macambira 2004), apresenta complexa trama geológica-estrutural e diversificados depósitos minerais, sendo assim, denominada de Província Polimetálica de Carajás (Dardenne \& Schobbenhaus 2000). Nos últimos anos se tornou uma das regiões melhor estudadas da Amazônia e a mais importante província mineral do país (Dall'Agnol et al. 2006), em virtude de suas inúmeras riquezas minerais. Ela pode ser dividida em dois domínios tectônicos: norte e sul. O primeiro se refere ao Cinturão de Cisalhamento Itacaiúnas $(\mathrm{CCl})$ composto de rochas metavulcânicas, formações ferríferas bandadas e granitóides, e o segundo ao terreno granito-greenstone Rio Maria, onde está localizada a área de estudo. 


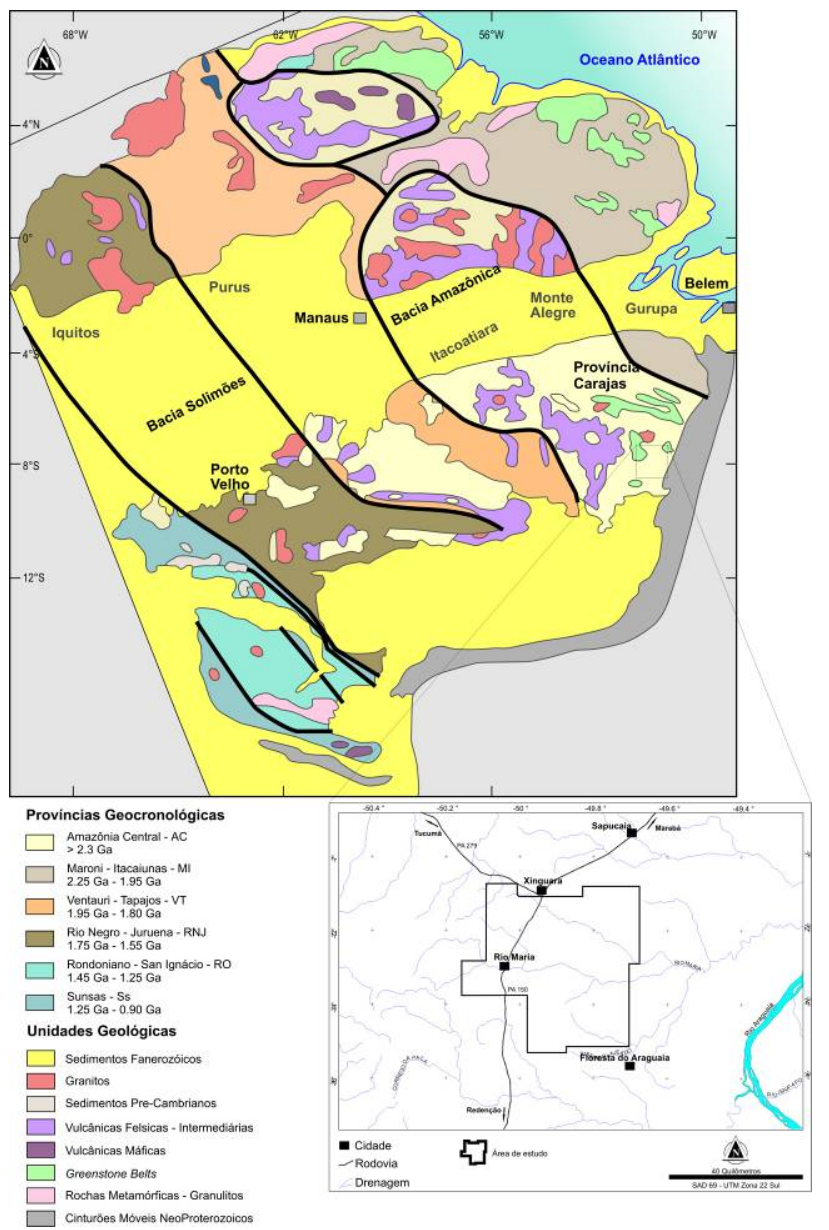

Figura 1 - Mapa simplificado do Cráton Amazônico, mostrando a localização da área investigada, representada pelo polígono em preto, coincidente com a área do levantamento aerogeofísico de alta resolução (Figura extraída de Tassinari \& Macambira 1999).

O Supergrupo Itacaiúnas é conhecido por conter a maior variedade de ocorrências e depósitos minerais da Província Mineral de Carajás. Diferentes tipos de depósitos de ouro, a maioria associadas às seqüências metavulcano-sedimentares arqueanas, incluindo greenstone belts de idade acima de 2,9 Ga, incluem (1) Fe-oxide poor Cu-Au, (2) Fe-oxide-Cu-Au-U-REE (3), Shear-zone related lodegold e, (4) sedimentary rock-hosted Au-PGE. Em contraste, a maioria das mineralizações auríferas do sul do Pará, hospedadas no terreno granito-greenstone Rio Maria, é descrita na literatura como do tipo lode, encaixadas em rochas metavulcânicas básicas e intermediárias e relacionadas a zonas de cisalhamentos (Huhn 1991; Oliveira 1987; Souza 1995). Nesta região também existem mineralizações de ouro associadas à intrusões calci-alcalinas no contato entre o Granodiorito Cumaru e o greenstone belt de Gradaús (Santos 1995). Os principais depósitos de ouro desse bloco incluem Sapucaia, Cumaru, Mamão-Babaçu, Malvinas, Tucumã e Inajá ( $<17$ t Au). Eles são caracterizados por pequenos depósitos de metais base e ouro e geralmente ocorrem como veios de quartzo gerados em domínios transtensionais de zonas de cisalhamento transcorrentes, com posterior movimentação reversa (Huhn 1991).

A Província Rio Maria é formada por sequências supracrustais do tipo greenstone belt e granitóides, ambos de idade arqueana, sendo intrudidos por diques e sills de idade paleoproterozóica. As seqüências vulcanossedimentares, agrupadas sob a denominação Supergrupo Andorinhas, ocorre em faixas alongadas de direção NW/SE, são compostas por basaltos komatíticos e toleiíticos, e estão cortados por intrusões cálcioalcalinas (Figura 2). Neste domínio ocorrem depósitos de ouro do tipo lode de pequeno porte (Mamão, Babaçu, Lagoa Seca, Diadema, Serrinha, etc).

O Supergrupo Andorinhas ocorre principalmente a leste da cidade de Rio Maria na Serra das Andorinhas, na região de Gradaús, Sapucaia, Seringa e a sul da Serra Pelada. Subdivide-se em dois Grupos, Babaçu na base e Lagoa Seca no topo. O Grupo Babaçu pode ser subdividido em Formação Igarapé Encantado, na base, e Formação Mamão no topo. A Formação Igarapé Encantado é constituída por derrames komatiiticos com textura spinifex e intercalações de formações ferríferas bandadas e compõem os greenstone belts de Seringa (Huhn et al. 1986) e Identidade (Souza et al. 1997). A Formação Mamão é constituída por metatufos, extensos derrames de metabasaltos toleíticos variolíticos, com pillow e intercalação de BIF's e talco-xistos, que predominam no topo da seqüência. Toda a seqüência é intrudida por diques de dioritos e doleritos (Huhn 1992).

O Grupo Lagoa Seca é localizado na porção sul do sinclinal Andorinhas. Este grupo é constituído pelas Formações Fazenda do Quincas e Recanto Azul constituem o Grupo (Nascimento \& Biagini 1988). A primeira, basal, é constituída por rochas metassedimentares clásticas (grauvacas e siltitos) intercaladas com metavulcânicas ultramáficas (talcoclorita-xistos), alem de níveis restritos de metavulcânicas intermediárias a félsicas (andesitos, dacitos, riodacitos), ao passo que a Formação Recanto Azul (superior) constitui-se de uma seqüência de rochas metavulcânicas/sub-vulcânicas intermediárias a félsicas, intercaladas com rochas metassedimentares predominantemente clásticas (grauvacas e siltitos), e níveis esporádicos de rochas metavulcânicas ultramáficas-máficas. As rochas metavulcânicas félsicas desta formação, datadas pelo método U-Pb em zircão, revelaram idades de $2.904 \pm 22 \mathrm{Ma}$ (Macambira \& Lancelot 1992) e 2.979 \pm 5 Ma (Pimentel \& Machado 1994). 


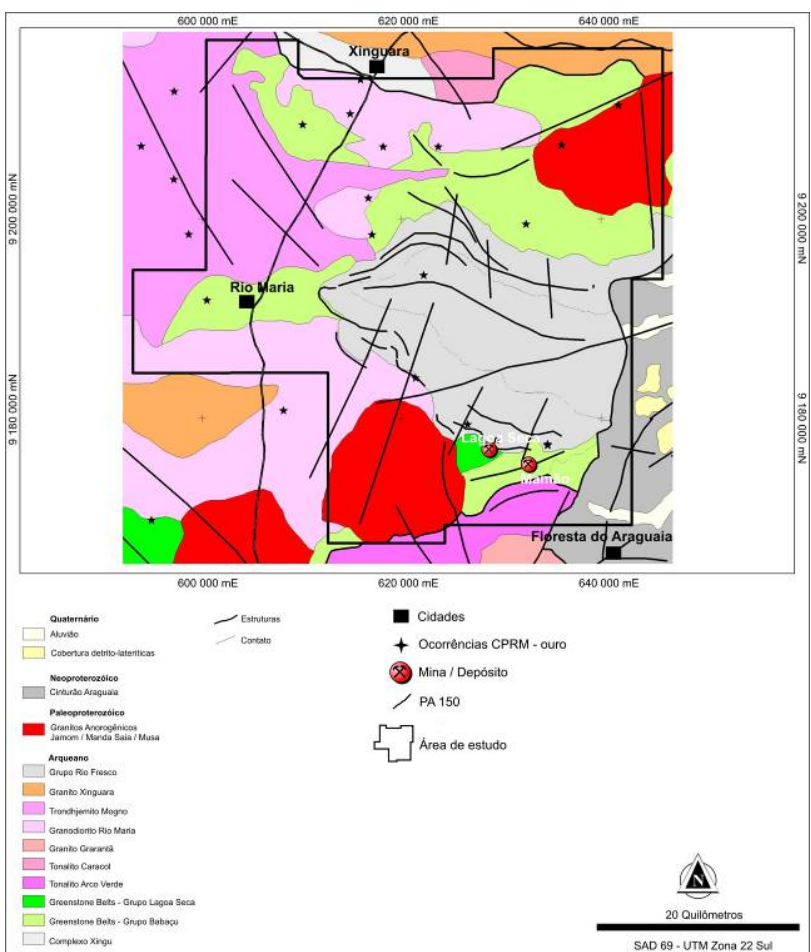

Figura 2 - Mapa geológico simplificado da área de estudo elaborado pela CPRM, ressaltando as ocorrências e depósitos de ouro na região (Vasques \& Rosa-Costa 2008)

\section{Materiais e métodos de trabalho}

O levantamento aerogeofísico foi efetuado pela empresa Lasa em Dezembro de 2007, sendo contratada pela Reinarda Mineração Ltda, empresa do Grupo Troy Resources NL da Austrália. A área de estudo foi recoberta com dados aerogeofísicos magnéticos gradiométricos e gamaespectrométricos de alta resolução com o objetivo de identificar novos alvos auríferos nesta porção do greenstone belt Andorinhas. A altura de vôo foi fixada em $100 \mathrm{~m}$ sobre o terreno. As linhas de vôo estão espaçadas de $125 \mathrm{~m}$ e as de controle, de $1.500 \mathrm{~m}$ com direções NS e EW, respectivamente. A área coberta é de aproximadamente 1.952 km2, a qual envolve 16.924 km lineares.

O processamento dos dados foi subdividido em três etapas: a primeira denominada pré-processamento, seguida pelo processamento de dados ou geração de produtos e, por último, a integração e interpretação dos produtos gerados. $\mathrm{Na}$ primeira etapa verificou-se possíveis inconsistências dos dados utilizando os testes denominados de Diferença 4 e Teste P. Não foram verificados dados espúrios dentro da base de dados. Posteriormente, os dados foram interpolados em malhas regulares utilizando o método da curvatura mínima e, posteriormente, micronivelados utilizando o algoritmo de Minty, modificado por Blum (1999).

Os produtos gerados a partir dos dados magnéticos consistem nos mapas transformados do campo magnético residual: amplitude do sinal analítico de ordem zero - ASA, o gradiente vertical calculado a partir do campo magnético residual - Dz (Figura 9), inclinação do sinal analítico - ISA (Figura 11) e amplitude do gradiente horizontal total - AGHT. Esses produtos foram utilizados na confecção do mapa de lineamentos magnéticos, tendo como base, principalmente, a imagem da inclinação do sinal analítico, a $1^{\text {a }}$. derivada vertical, e os gradientes horizontais medidos em X e Y - Gx e Gy (Figura 3). O gradiente horizontal medido em X - Gx (Figura 10) é bastante usado para ressaltar os baixos magnéticos típico das zonas de cisalhamento uma vez que a percolação de fluidos destrói a magnetita havendo uma desmagnetização do sistema.

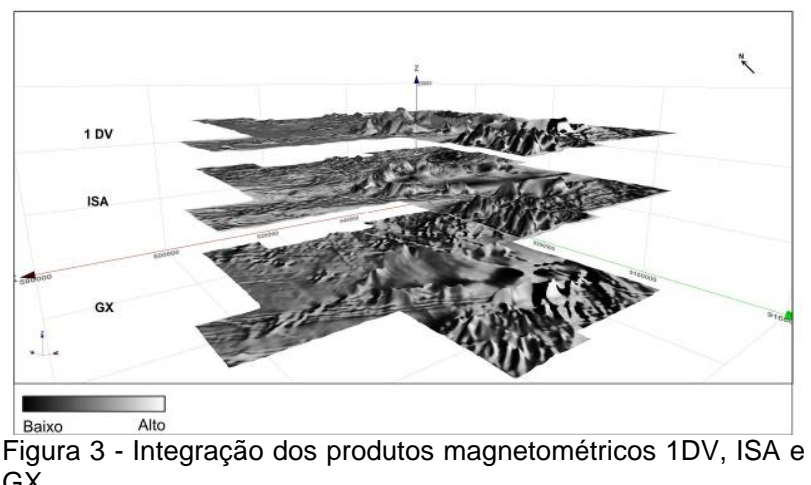
$\mathrm{GX}$

Os dados gamaespectrométricos, incluindo os canais de contagem total $(\mathrm{CT})$, potássio $(\mathrm{K})$, equivalente de tório (eTh) e equivalente de urânio (eU) foram interpolados em malhas regulares utilizando o método da curvatura mínima e posteriormente micronivelados.

Além de imagens em pseudocor dos canais citados anteriormente, o tratamento gamaespectrométrico consistiu na geração da composição ternária RGB (Figura 4), para auxiliar no mapeamento geológico e também o Parâmetro "F".

O Parâmetro "F" mostra a distribuição do potássio em relação aos radioelementos urânio e tório e vem sendo utilizado na discriminação de zonas de alteração hidrotermal. Parâmetro " $F$ " se baseia na seguinte expressão:

\section{$\mathbf{F}=\mathrm{K}$ * eU/eTh}

Efimov (1978 apud Gnojek \& Prichystal 1985) propôs uma série de relações entre os radioisótopos, destacando que a expressão acima permite ressaltar o enriquecimento de potássio e urânio em relação ao tório, podendo indicar áreas com alteração hidrotermal associadas à mineralizações. As primeiras aplicações deste parâmetro em corpos granitóides no Brasil foram realizadas por Pascholati (1990) e Ferreira (1991). 


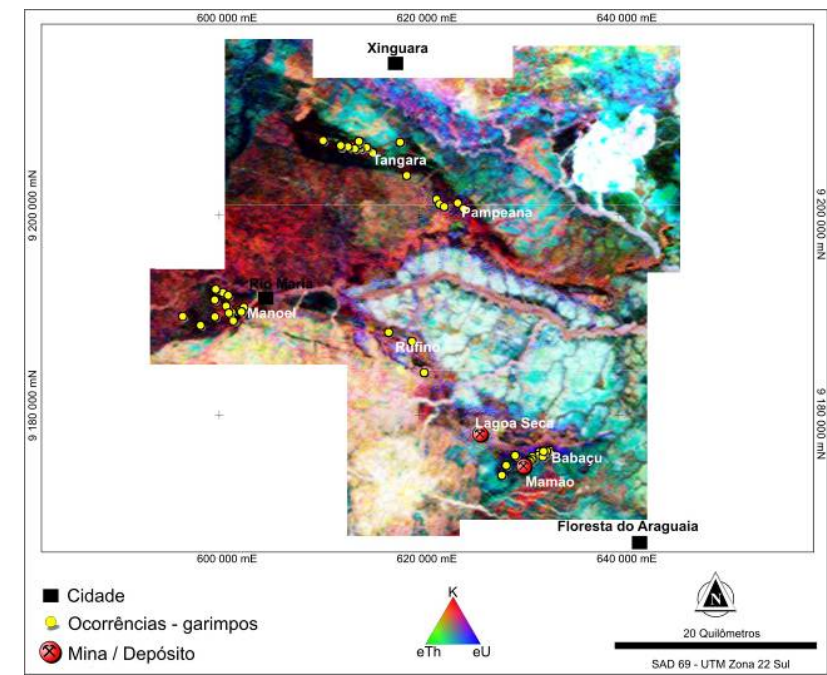

Figura 4 - Imagem ternária em falsa cor no padrão RGB: K, Th e $\mathrm{U}$ nas cores vermelho, verde e azul respectivamente, mostrando as ocorrências minerais e principais depósitos.

\section{Resultados}

Os dados aeromagnetométricos foram utilizados para a caracterização do arcabouço estrutural da área com a geração de um mapa de lineamentos magnéticos (Figura 5). Sobrepondo as ocorrências de ouro no mapa de lineamentos magnético gerado observa-se que a maioria das ocorrências são estruturalmente controladas associadas a áreas de intensa movimentação de lineamentos. De forma geral, os lineamentos magnéticos identificados podem representar contatos, empurrões e zonas de cisalhamento.

Os lineamentos foram classificados hierarquicamente como de primeira ordem e segunda ordem. Os de primeira ordem possuem direção NW-SE. Os de segunda ordem apresentam direção geral para NE-SW. As estruturas são cortadas por lineamentos rúpteis na direção N-S.

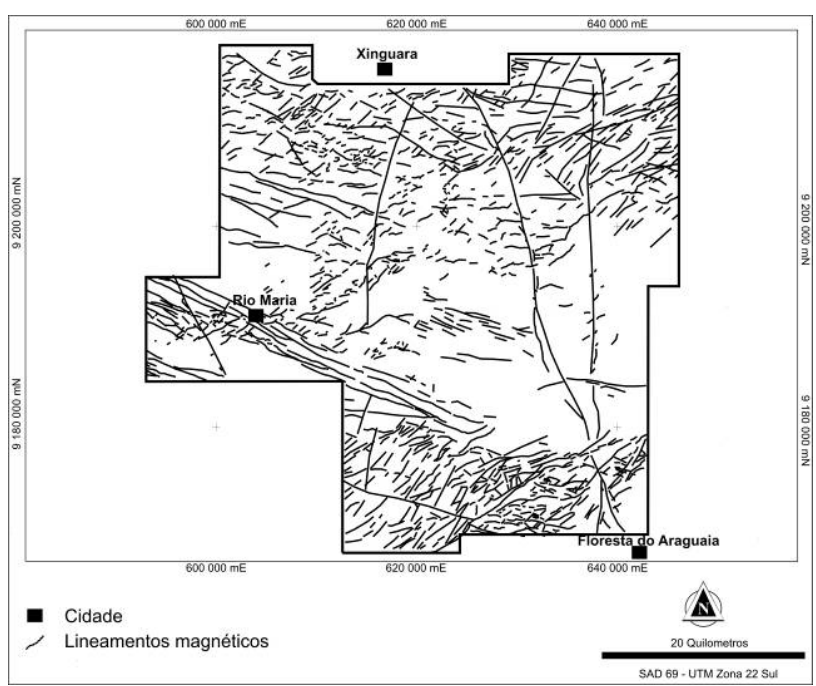

Figura 5 - Mapa de lineamentos magnéticos gerados a partir da interpretação das imagens 1DV, ISA, GX e GY.
Os dados aerogamaespectrométricos foram utilizados para identificar possíveis zonas de alteração hidrotermal, com concentrações anômalas de potássio, dentro das diferentes unidades que compõem o greenstone belt. O principal processo natural de enriquecimento do potássio deve-se à alteração hidrotermal. O potássio ocorre naturalmente concentrado em zonas de alteração hidrotermal, já o tório caracteriza-se por ser o elemento mais imóvel dentre os três detectados em gamaespectrometria, podendo ser utilizado como guia para determinar as concentrações normais de cada material. A normalização do potássio em relação ao tório permite a eliminação do efeito litológico primário e a determinação de concentrações anômalas daquele elemento (Carvalho 2006).

\section{Discussão e Conclusões}

A integração da imagem do Parâmetro "F", das unidades que compõem o greenstone, com gradiente horizontal medido (Gx) mostra que zonas mineralizadas conhecidas são mapeadas pelos altos valores no Parâmetro "F" e baixos gradientes magnéticos segundo a direção NW-SE das estruturas de primeira ordem e segundo a direção NE-SW das estruturas de segunda ordem (Figura 6).

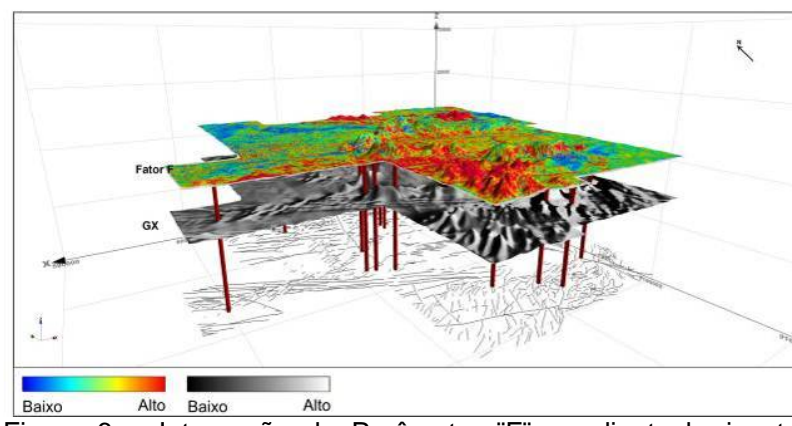

Figura 6 - Integração do Parâmetro "F", gradiente horizontal medido em $X(\mathrm{Gx})$ e lineamentos magnéticos para a seleção dos alvos.

Com base nessa premissa foram selecionados 16 alvos exploratórios para serem investigados em campo. Os alvos estão estruturalmente controlados segundo as direções de zonas de cisalhamento de primeira e segunda ordem (Figura 7).

Dos 16 alvos gerados 4 deles já foram pesquisados. A integração com os dados de campo nesses alvos pesquisados mostram que estão localizados em zonas de cisalhamento com alteração hidrotermal de alto potássio (Figura 8), correlacionados a unidades félsicas e/ou máficas cisalhadas com enriquecimento secundário em biotita e sericita. Diversas amostras de rocha foram coletadas e analisadas, sendo que o melhor teor encontrado foi de $20.67 \mathrm{~g} / \mathrm{t}$ ouro e várias outras amostras anômalas com teores variando entre 0.33 - $1.73 \mathrm{~g} / \mathrm{t}$ ouro. Esses valores confirmam a eficiência da utilização de dados aerogeofisicos na geração de alvos para prospecção mineral. 


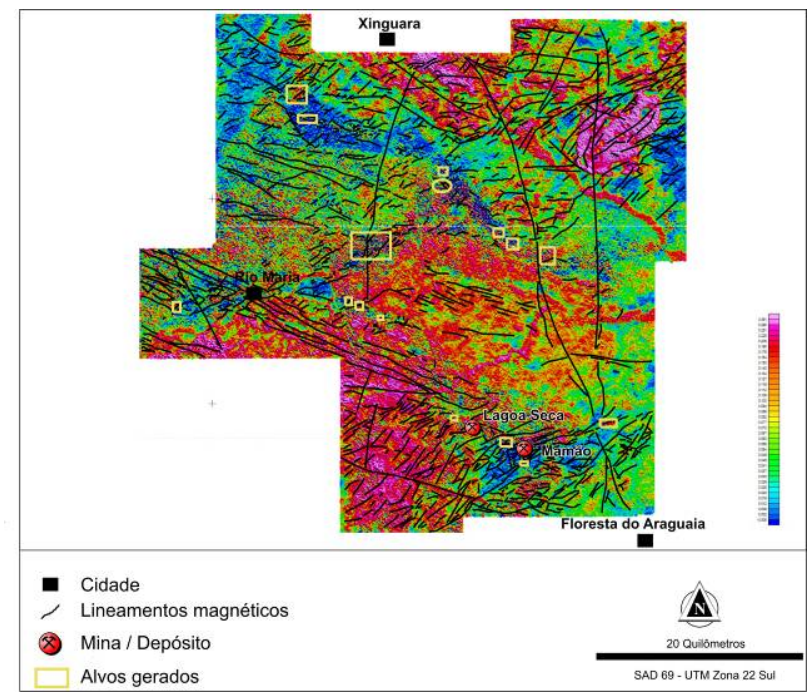

Figura 7 - Imagem do Parâmetro "F" com a localização dos 16 alvos exploratórios gerados. Os alvos foram selecionados baseados na inspeção visual, a partir de uma avaliação da configuração estrutural e de geologia favorável dentro da seqüência vulcano-sedimentar do greenstone Andorinhas.

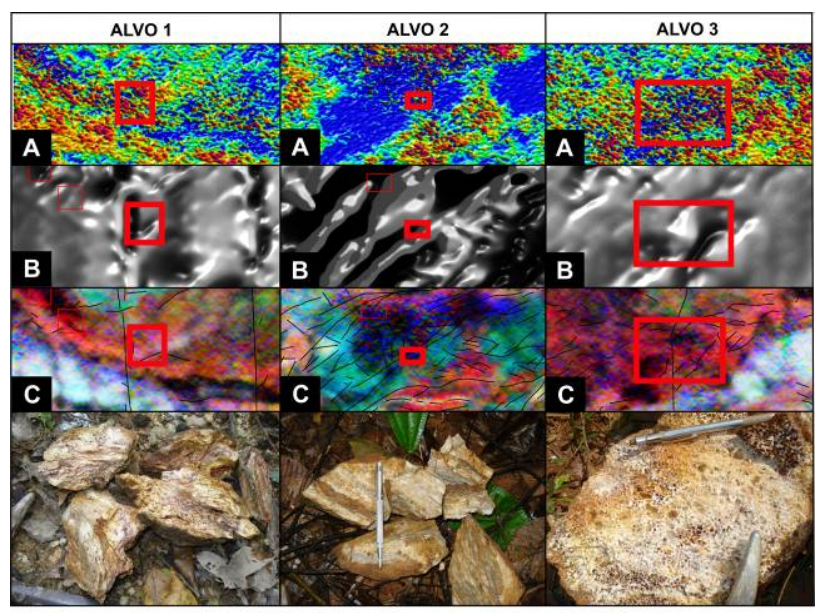

Melhor alvo validado no campo

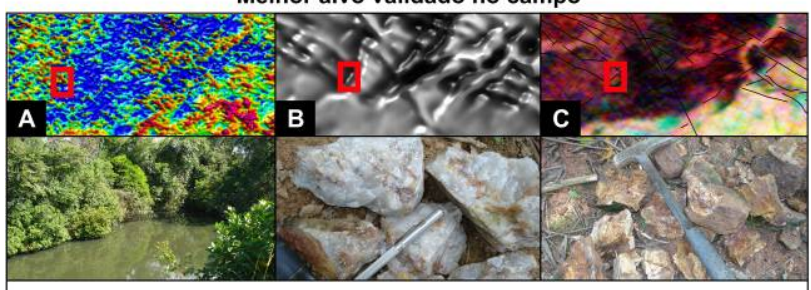

A - Fator "F"

B - GX

C. - Estruturas sobre imagem Ternária RGB

Figura 8 - Detalhes com fotos de 4 alvos gerados e já pesquisados no campo. A - imagem do Parâmetro $F, B$ - imagem do gradiente medido em $X(G x)$, C- estruturas geológicas interpretadas sobre imagem ternária. No melhor alvo gerado com amostra de rocha de até $20.67 \mathrm{~g} / \mathrm{t}$ Au havia um garimpo antigo desconhecido até a integração dos dados.

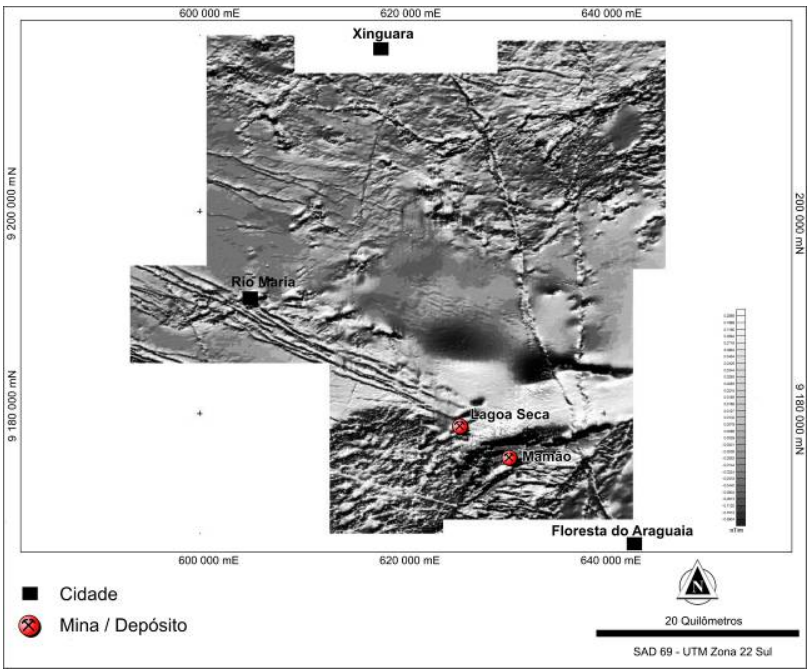

Figura 9 - Imagem da derivada vertical de primeira ordem (1DV) do campo magnético anômalo.

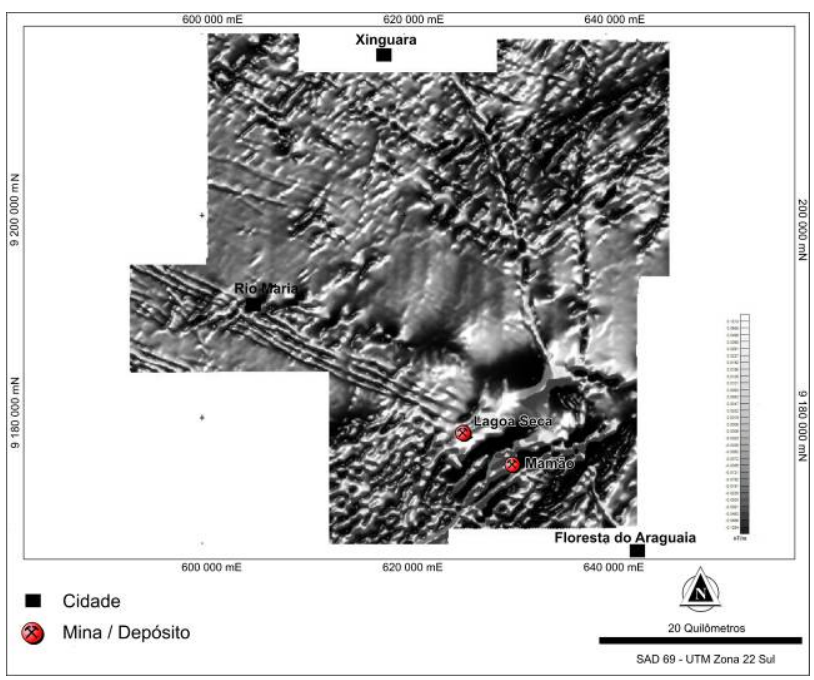

Figura 10 - Imagem do gradiente horizontal medido em X (GX). 


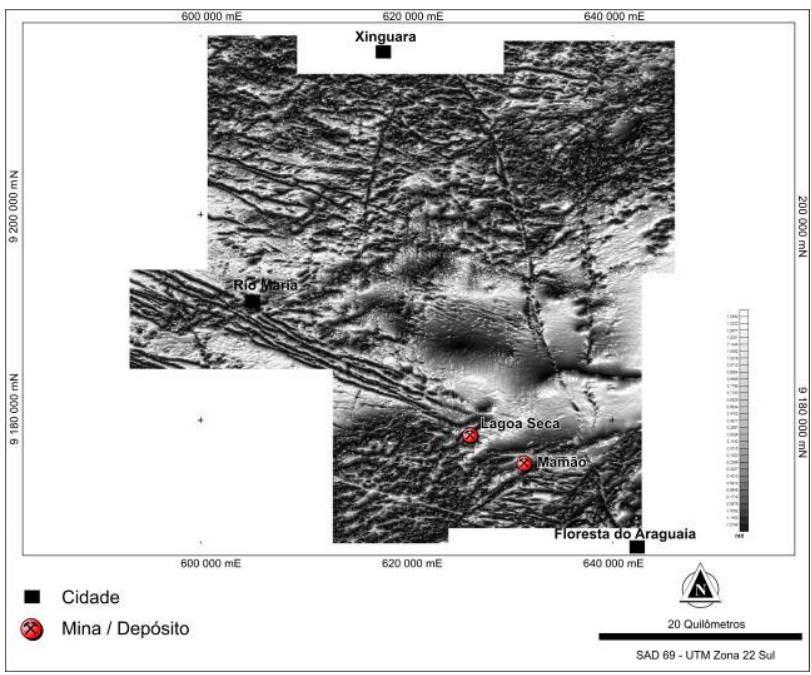

Figura 11 - Imagem da inclinação do sinal analítico (ISA).

\section{Referências}

Almeida, F.F.M., Hasui, Y., Brito Neves, B.B. \& Fuck, R., 1981. Brazilian structural provinces, an introduction. Earth Sci. Rev. 17, 1-29.

Blum, M. L. B. 1999. Processamento e Interpretação de dados de geofísica aérea no Brasil Central e sua aplicação à Geologia regional e à prospecção mineral. Brasília. Tese de Doutorado, Instituto de Geociências, UnB, 229p.

Carvalho, L. M. M. 2006. Integração de dados de geofísica aérea aplicada a geologia e à prospecção mineral no Distrito Esmeraldífero de Itabira-ferros, Quadrilátero Ferrífero, MG. Tese de Doutorado, Instituto de Geociências, UnB,

Dall'Agnol R., Oliveira M.A., Almeida J.A.C., Althoff F.J., Leite A.A.S., Oliveira D.C., Barros C.E.M., 2006. Archean and Paleoproterozoic granitoids of the Carajás metallogenetic province, eastern Amazonian Craton. In: R. Dall'Agnol, L.T. Rosa- Costa, E.L. Klein (eds.). Symposium Magmatism, Crustal Evolution and Metallogenesis of the Amazonian Craton. Abstracts Vol. and Field Trips Guide. Belém, PRONEX-UFPA/ SBG-NO, $150 p$.

Dardenne, M. A. \& Schobbenhaus, C. 2000. The metallogenesis of the South American platform. In: CORDANI UG, MILANI EJ, THOMAZ FILHO A \& CAMPOS DA. (Ed.). Tectonic Evolution of South America. 31 International Geological Congress, 755-850, Rio de Janeiro-RJ.

Ferreira F.J.F. 1991. Aerogamaespectrometria e aeromagnetometria de um trato ocidental do Précambriano paulista. Instituto de Geociências, Universidade de São Paulo, São Paulo, Tese de Doutoramento, $150 \mathrm{p}$.
Gnojek, I. \& Prichystal, A. 1985. A new zinc mineralization detected by airborne gamma-ray spectrometry in Northern Moravia (Czechoslovakia). Geoexploration, 23(4): 491-502.

Huhn, S.R.B., Martins, L.P.B. \& Montalvao, R.M.G., 1986. Caracterizações petrograficas, texturais e estruturais dos fluxos mafico-ultramaficos do greenstone belt Seringa, sul do Estado do Pará. In: 34th Congr. Bras. Geol., SBG, Goiânia. Proceedings, vol. 2, pp. 648-662.

Huhn, S.R.B., 1992. Geologia, controle estrutural e gênese do depósito aurífero Babaçu, região de Rio Maria, sul do Pará. UnB, Brasília, Dissertação de Mestrado, $169 p$.

Nascimento, J.S. \& Biagini, D.O., 1988. Conhecimento atual da jazida de ouro de Lagoa Seca, sul do Pará. In: Cong. Bras. Geol., 35, Belém, 1988. Anexo aos Anais... Belém, SBG, p.143-155.

Oliveira, C.G. 1987. Mineralizações auríferas da anomalia de Diadema, Pará. Brasília, Dissertação de Mestrado, Universidade de Brasília, 93p.

Pascholati E.M. 1990. Caracterização geofísica da Suíte Intrusiva de Itu. Instituto Astronômico e Geofísico, Universidade de São Paulo, São Paulo, Tese de Doutoramento, 135p.

Pimentel, M.M. \& Machado, N., 1994. Geocronologia U$\mathrm{Pb}$ dos terrenos granito-greenstone de Rio Maria, Pará. Congresso Brasileiro de Geologia, Camboriu, pp. 390391.

Robert, F., Brommecker, R., Bourne, B. T., Dobak, P. J., Mcewan, C. J., Rowe, R. R., Zhou, X., 2007. Models and Exploration Methods for Major Gold Deposit Types, in Proceedings of Exploration 07: Fifth Decennial International Conference on Mineral Exploration, edited by B. Milkereit, 2007, p. 691-711

Souza, Z.S., Dall'Agnol, R., 1995. Geochemistry of metavolcanic rocks in the Archean greenstone belt of Identidade, SE Pará, Brazil. An. Acad. Bras. Ciênc. 76, 217-233.

Souza, Z.S., Dall'Agnol, R., Oliveira, C.G. \& Huhn, S.R.B., 1997. Geochemistry and petrogenesis of metavolcanic rocks from Archaean greenstone belts: Rio Maria region (Southeast Pará, Brazil). Rev. Bras. Geoc. 27, 169-180.

Tassinari, C.C.G. \& Macambira, M.J.B., 1999. Geochronological Provinces of the Amazonian Craton. Episodes 22, 174-182. 